\title{
Simulation of Microstructure of As-cast Steels in Continuous Casting
}

\author{
Seppo LOUHENKILPI, Jyrki MIETTINEN and Lauri HOLAPPA \\ Helsinki University of Technology, Laboratory of Metallurgy, P.O. Box 6200, FIN-02015 TKK, Finland. \\ E-mail: seppo.louhenkilpi@tkk.fi
}

(Received on November 30, 2005; accepted on March 9, 2006)

\begin{abstract}
Prediction and control of steel microstructure during and after the continuous casting process is an extremely important task for steel producers making special steels with high quality demands. Continuous casting is a very complex process with series of parallel phenomena with heat and mass transfer, solidification and phase transformations. As a long-term project the authors have proceeded by developing first a two-dimensional heat transfer model, then a three-dimensional and finally, a dynamic three-dimensional heat transfer model to simulate the continuous casting process. A special solidification model was developed as well, and coupled with the heat transfer model. Models were experimentally validated and numerous industrial cases were calculated and compared with measurements. The models seemed to predict quite accurately the phase transformations and micro-structural features like dendrite arm spacing and austenite grain size, phase fractions and hardness throughout the whole as-cast strand.
\end{abstract}

KEY WORDS: continuous casting; modeling; heat transfer; microstructure; grain size.

\section{Introduction}

Computational models are nowadays increasingly used to simulate metallurgical processes. Continuous casting process is a good example of a complex series of parallel phenomena including heat and mass transfer processes, solidification, phase transformations etc. For practical purposes, heat transfer models have been developed and successfully applied to simulate steady state casting operations in off-line. For better control over the whole continuous casting cycle, more attention has been focused on developing advanced heat transfer models which are valid under transient casting conditions. By including a microstructure model in the model for continuous casting process, the micro-structural evolutions throughout the strand can be predicted as a function of steel composition and process variables. It is well recognized that maintaining a strict micro-structural control is of importance in the quality of continuously cast products. At the Helsinki University of Technology, a 3-dimensional steady state model (TEMPSIMU3D) and a transient heat transfer model (DYN3D) were developed as well as a model for solidification, phase transformation and microstructure (IDS). The IDS model was coupled to the steady state heat transfer simulations to predict the phase transformations and microstructure data (dendrite diameter, austenite grain size) in continuous casting throughout the whole strand. The hardness distribution in the as-cast strand can also be predicted using empirical equations. The heat transfer models were developed in cooperation with University of Jyväskylä. Characteristics of the models and some results of the calculations are present- ed in this paper.

\section{Heat Transfer Models for Continuous Casting}

TEMPSIMU3D and DYN3D are 3-dimensional heat transfer models for continuous casting. ${ }^{1-4)}$ The first model is for steady state casting and the second one for transient casting conditions with a capability to be used in real-time. The model equations include the transient term but in the case of the steady state model, this term is neglected. The models consist of two separate modules: the mould model and the strand model. They are run iteratively. The heat transfer coefficient across the air gap between the mould and the solidifying shell is described as a function of the strand surface temperature and is thus used to couple the modules. Models are based on the finite difference method where an upwind scheme is used for the convection term and a seven point finite difference approximation is used for the rest of the terms. Nonlinear equations are solved by using nonlinear Gauss-Seidel-Newton method. The strand model simulates the strand temperature field and the temperature related data three-dimensionally according to Eq. (1) (the term $\rho \cdot \partial H / \partial t$ is neglected in the steady state model).

$$
\begin{aligned}
\rho \frac{\partial H}{\partial t}+ & v \frac{\partial H}{\partial z} \\
& =\frac{\partial}{\partial x}\left(k_{\text {eff }} \frac{\partial T}{\partial x}\right)+\frac{\partial}{\partial y}\left(k_{\text {eff }} \frac{\partial T}{\partial y}\right)+\frac{\partial}{\partial z}\left(k_{\text {eff }} \frac{\partial T}{\partial z}\right)
\end{aligned}
$$


Here $H$ is the enthalpy, $t$ is time, $k_{\text {eff }}$ is the effective thermal conductivity, $T$ is temperature, $\rho$ is density and $v$ is the actual casting speed. The enthalpy function $H$ includes also the effect of all phase transformations. The convective heat transfer in the liquid pool due to the liquid flow is described with the effective thermal conductivity according to Eq. (2).

$$
k_{\mathrm{eff}}=k \cdot f_{\mathrm{S}}+A \cdot k \cdot\left(1-f_{\mathrm{S}}\right) \text {. }
$$

where $A$ is a constant and $f_{\mathrm{S}}$ is the solid fraction in the mushy zone. If the constant $A$ is 1 , there is no increased heat transfer in the mushy or liquid regions due to the liquid convection. This means that the liquid pool is stagnant, i.e. there is no mixing in the liquid phase. For slab casters, we have used a value of 1.5 and for bloom casters with mould electromagnetic stirring a value of 2 . The boundary condition for the strand in the mould is given by Eq. (3), where $\partial n$ is $\partial x$ for the narrow face and $\partial y$ for the wide face.

$$
-k \frac{\partial T}{\partial n}=h_{\text {gap }}\left(T-T_{\text {ext }}\right)
$$

Here $h_{\text {gap }}$ is the gap heat transfer coefficient, $T$ is the strand surface temperature and $T_{\text {ext }}$ is the external temperature, in this case the temperature of the mould surface. The gap heat transfer coefficient is a function of the strand surface temperature and it is defined so that the measured and calculated mould heat flux values are similar for the simulated case. It can be calculated using an inverse analysis procedure if thermocouple measurements are available or by trial and error. The measured values can be calculated from the heat balance of the mould cooling water. Equation (3) is also used as the boundary condition for the hot side of the mould, where $h_{\text {gap }}$ is the same gap heat transfer coefficient as for the strand model but $T$ is the mould surface temperature and $T_{\text {ext }}$ is now the temperature of the strand surface, which is calculated by the strand model. For the colder side, a similar equation is used, but $T_{\text {ext }}$ is the temperature of the cooling water and $h$ is a constant and it depends among other things on the mould water flow rate. It is defined according to experimental measurements as $h_{\text {gap }}$ values. It is assumed that there is no heat flux through the top and the bottom surfaces of the mould. The mould temperatures are calculated by the mould model according to Eq. (4) (the term $\rho c \cdot \partial T / \partial t$ is neglected in steady state model).

$$
\rho c \frac{\partial T}{\partial t}=k \frac{\partial^{2} T}{\partial x^{2}}+k \frac{\partial^{2} T}{\partial y^{2}}+k \frac{\partial^{2} T}{\partial z^{2}}
$$

The model allows the defining of three different material layers in the mould. This is especially important when the same model is applied for continuous casting of copper where there is usually at least a copper jacket with a graphite die. In the secondary cooling zone after the mould the model has been divided into calculation domains between a pair of support rolls. This domain has been divided into four different cooling regions: roller contact area, prenozzle area, spraying area, after spray and pool water area (post-nozzle area). Roller contact area involves heat conduction from strand to roll. Roller heat transfer depends on the roll contact length in the casting direction as well as the roll cooling mode. Three different roll types can be used. The boundary condition for the roll cooling is given by Eq. (5):

$$
-k \frac{\partial T}{\partial n}=h\left(T-T_{\mathrm{ext}}\right)
$$

Here, $\partial n$ is $\partial x$ for the narrow face and $\partial y$ for the wide face. As to the roll contact length and roll external temperature, the values of $5 \mathrm{~mm}$ and $25^{\circ} \mathrm{C}$ were used. The $h$ values used varied between $0.3-3.6\left(\mathrm{~kW} / \mathrm{m}^{2} \mathrm{C}\right)$ depending on the roll type. The heat flux extracted by roll internal cooling water is made up of radiation and contact heat transfer. About $60 \%$ of heat flux is by contact, $40 \%$ is by radiation. Outside the roll contact area, at all exposed surfaces, TEMPSIMU calculates the radiant heat losses, based upon the Stefan-Boltzmann law. This covers the radiation part of the roll heat flux. Pre-nozzle and post-nozzle areas account for the indirectly cooled space between the roller pairs. The boundary equation for these areas is defined by

$$
-k \frac{\partial T}{\partial n}=h\left(T-T_{\mathrm{ext}}\right)+\varepsilon \sigma\left(T^{4}-T_{\mathrm{air}}^{4}\right)
$$

Here $h$ is the heat transfer coefficient for air convection, which is the minimum value used for all exposed surfaces in the machine. A default value for this is $0.04 \mathrm{~kW} / \mathrm{m}^{2} \mathrm{C}$. $T_{\text {ext }}$ is the external temperature, $\varepsilon$ is the emissivity, and $T_{\text {air }}$ is the air temperature. For the post-nozzle area the heat transfer coefficient for flowing water is used. This takes into account the heat transfer to the flowing water on the strand after the nozzles. The flowing water $h$ is defined with the nozzle data and the values are on the average in the range of $0.05-0.3 \mathrm{~kW} / \mathrm{m}^{2} \mathrm{C}$ depending on the spray type, amount of water etc. In the spraying area, the strand is usually cooled by a spray of water or water-air mixture. Nozzle parameters like air and water flow have an effect on the cooling efficiency. The mechanisms of cooling can be subdivided into heat transfer by radiation and convection. The radiation heat flux parameters, emissivity and the air temperature are the same as defined for the pre-nozzle area. The heat transfer coefficient for the water spraying area is defined by

$$
h=a \cdot W^{b} \cdot c(T)
$$

Here $h$ is the water spray heat transfer coefficient, $W$ the water flow rate, $\mathrm{m}^{3} / \mathrm{h}$, and $a, b$ and $c$ are parameters. For instance, for air-mist sprays (in the range of stable film boiling) the following parameters are used: $a=0.133, b=0.724$, and for water-only sprays: $a=0.110, b=0.64$. The parameter $c$ is a function of temperature and it takes into account the effect of the strand surface temperature on the heat transfer coefficient (Leidenfrost effect). Default values for $c$ used were: 4.5 at $400^{\circ} \mathrm{C}, 2.45$ at $600^{\circ} \mathrm{C}, 1.8$ at $700^{\circ} \mathrm{C}, 1.3$ at $800^{\circ} \mathrm{C}$ and 1 at $900^{\circ} \mathrm{C}$. Linear interpolation was used between these values.

\subsection{Material Data}

To obtain reliable results from the heat transfer simulations, accurate thermo-physical material data are needed. Usually these data are obtained from literature but very seldom all required data are found. The use of inaccurate material data can lead to considerable errors in calculations as presented by. ${ }^{5)}$ Typical data needed are the density, the ther- 
mal conductivity, the specific heat, the phase transformation temperatures and the corresponding latent heats as well as the information how the latent heat is released during a phase transformation. The materials data used in the presented simulations were calculated using the IDS package presented in chapter 3 .

\subsection{Validation of the Heat Transfer Models}

The novel 3-dimensional simulation model TEMPSIMU3D is based on the earlier developed tool, TEMPSIMU2D ${ }^{6)}$ which is a two-dimensional slice model which calculates the strand temperatures and the shell thickness in the two-dimensional cross-sections of the strand on its way through the casting machine. The casting direction is treated as the time dimension. TEMPSIMU2D is widely used in industry and academically world wide. It has been validated by the developers and by the users. The developers validated the model by measuring shell thicknesses and surface temperatures in different locations of the strand. Shell thickness was determined by developing and using a wedge technique and temperatures were measured with pyrometers. In the wedge technique, a wedge is inserted between two rolls of a caster. As the strand moves on, the wedge moves between the roll and the strand. The wedge causes a depression in the strand shell which results in tensile stress and in formation of cracks at the solidification front of the shell. The ambient shell thickness is then determined from the crack tip locations in the cross-cut specimens from the strand. A more detailed description of the wedge technique is given in. ${ }^{7,8)}$ The simulations with TEMPSIMU2D showed good agreement with the shell thickness and temperature measurements (Fig. 1). The experimental conditions in Fig. 1 were the following: casting speed $1.30 \mathrm{~m} / \mathrm{min}$, curved slab caster, mould dimensions $210 \mathrm{~mm} \times 1275 \mathrm{~mm}$, low-alloyed
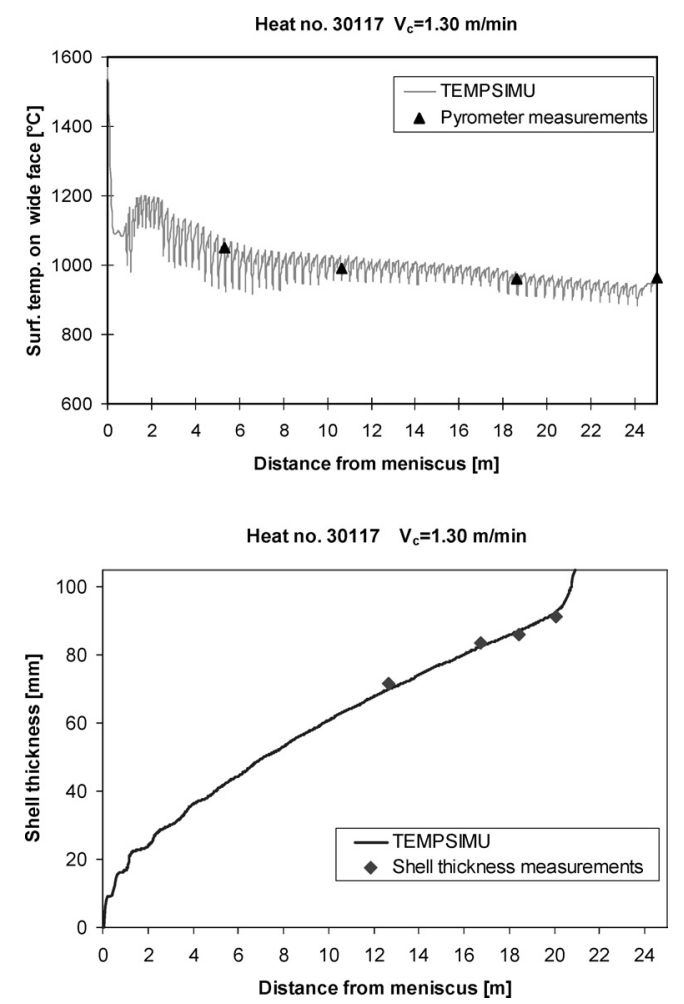

Fig. 1. Temperature and shell thickness profiles with measured data points. $3,7,8)$ carbon steel with carbon content of $0.081 \%$. The new model TEMPSIMU3D was validated by comparing the results with TEMPSIMU2D. That could be done, because in steels the heat flow along the casting direction $(z)$ is insignificant compared to that along the cross-sectional directions $(x, y)$ and hence $2 \mathrm{D}$ and $3 \mathrm{D}$ results should be relatively identical. The comparison really showed only very small differences in the results. The 3D model gave a bit smoother and narrower fluctuation in the surface temperature curve along the casting direction than the $2 \mathrm{D}$ due to the inclusion of the heat transfer in the $z$-direction. Highest values were observed at the nozzle and roll locations. The dynamic 3-dimensional model version DYN3D was validated by comparing the results with TEMPSIMU3D at steady state conditions. TEMPSIMU3D gives more accurate results especially in the mould compared to TEMPSIMU2D because TEMPSIMU3D has also the mould module and the heat transfer from the strand to the mould can be simulated much more accurately with it. Also an inverse analysis procedure can be used to define the gap heat transfer coefficient if thermocouple measurements are available. DYN3D is a similar model than TEMPSIMU3D but dynamic and it can be used to simulate dynamic process conditions like ladle changes and start and end of the casting

\section{IDS-Solidification and Microstructure Model for Steels}

The IDS solidification analysis package was developed at the Helsinki University of Technology. ${ }^{9-14)}$ The model is based on the thermodynamic and kinetic theories of solidification. It also utilizes assessed thermodynamic data as well as regression formulas of experimental data. The IDS software includes two main modules, the IDS module and the ADC module. Both modules have their own recommended composition ranges. The present version of the IDS module is valid for simulation of the solidification of low-alloyed steels and stainless steels ( $\mathrm{Cr}$ up to $24 \mathrm{wt} \%$ and $\mathrm{Ni}$ up to $16 \mathrm{wt} \%$ ). The model applies a thermodynamic substitutional solution model and magnetic ordering model and Fick's diffusion laws to determine the stable solution phases, liquid L, delta ferrite $\delta$ and austenite $\gamma$, and their fractions and compositions as a function of temperature. These calculations take into account the effect of solutes $\mathrm{C}, \mathrm{Si}$, $\mathrm{Mn}, \mathrm{P}, \mathrm{S}, \mathrm{Cr}, \mathrm{Mo}, \mathrm{Ni}, \mathrm{Cu}, \mathrm{Al}, \mathrm{N}, \mathrm{Nb}, \mathrm{Ti}, \mathrm{V}, \mathrm{Ca}, \mathrm{B}, \mathrm{O}$ and $\mathrm{H}$, cooling rate and dendrite arm diameter. Assuming complete solute mixing in liquid the calculations can be made in one volume element set on the side of a dendrite arm (Fig. 2). During solidification, the model also simulates the formation of certain binary compounds, such as MnS and TiN. At the phase interface, the model solves the thermodynamic equilibrium of two solution phases, $\delta$ and L, $\gamma$ and L, and $\gamma$ and $\delta$, using the chemical potential-equality equations for each component $(i=1, . ., n)$ of the alloy (Eq. (8)).

$$
\mu_{\mathrm{i}}^{\phi 1}\left(T, x_{1}^{\phi 1}, . ., x_{n}^{\phi 1}\right)=\mu_{\mathrm{i}}^{\phi 2}\left(T, x_{1}^{\phi 2}, . ., x_{n}^{\phi 2}\right) . .
$$

In the equation, $\mu_{i}^{\phi}$ is the chemical potential of the component $i$ in phase $\phi, x_{i}^{\phi}$ is the mole fraction of the component in phase $\phi, \mathrm{T}$ is temperature and $n$ is the number of components in the alloy.

ADC is a semi-empirical solid-state phase transforma- 


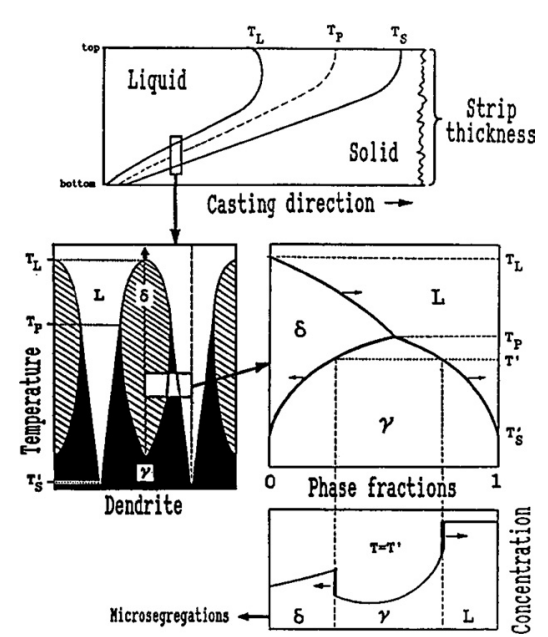

Fig. 2. Magnified portion of the mushy zone showing a volume element on the side of a dendrite arm and some results of the IDS calculations.

tion model for steel. It simulates the austenite decomposition process below $1000^{\circ} \mathrm{C}$. In the case of low-alloyed steels, the simulation involves the formation of pro-eutectoid ferrite, pro-eutectoid cementite, pearlite, bainite and martensite, and in the case of stainless steels, the formation of martensite only. The ADC model applies a thermodynamic substitutional solution and magnetic ordering model, a carbon diffusion model and special regression formulas based on the CCT experiments. The simulation takes into account the effect of solutes $\mathrm{C}, \mathrm{Si}, \mathrm{Mn}, \mathrm{Cr}$, Mo and $\mathrm{Ni}$, cooling rate and austenite grain size. The ADC model also calculates temperatures $\mathrm{Ae}_{3}$ and $\mathrm{A}_{\mathrm{cm}}$ taking into account the effect of the 18 solutes of IDS simulation mentioned above. The IDS package also calculates solidification-related thermo-physical properties (e.g. enthalpy, specific heat, density and thermal conductivity) from the liquid state down to the room temperature. The calculations of the IDS package have been validated with numerous experimental measurements.

- Calculation of Austenite Grain Size and Secondary Dendrite Arm Spacing

For low alloyed steels, one can estimate with IDS the ascast austenite grain size, $d_{\mathrm{G}}[\mu \mathrm{m}]$ according to Eq. (9).

$$
d_{\mathrm{G}}=1841-1836 \cdot \frac{\exp (\dot{T})}{1+\exp (\dot{T})}+3.44 \cdot 10^{-5} \cdot \exp \left(T^{\gamma / 80}\right)
$$

Here, $\dot{T}\left[{ }^{\circ} \mathrm{C} / \mathrm{s}\right]$ refers to the nodal cooling rates below the solidus temperature obtained with the heat transfer model and $T^{\gamma}\left[{ }^{\circ} \mathrm{C}\right]$ is the maximum temperature of the entirely austenitic structure calculated with IDS. The equation was empirically formulated using the measured grain size data of Yasumoto et al. and is based on their idea. ${ }^{15)}$ According to them, the grain growth of austenite occurs rapidly below a completion temperature of transformation into austenite phase, $T^{\gamma}$, since strong pinning effect of a second phase, such as delta ferrite and/or liquid on the austenite grain boundary migration disappears. Hence, the higher the value of this completion temperature, the longer the time period for the grain to grow during the cooling process. The equa- tion shows that the lower the cooling rate and the higher the value of $T^{\gamma}$, the coarser the grain size is. This trend is logical since a low cooling rate leaves more time for austenite grains to grow and a high temperature is related to higher growth rate. The exponential form was chosen for the cooling rate to prevent unrealistic predictions of $\mathrm{dG}$ beyond the studied cooling rate region of 0.5 to $1.5^{\circ} \mathrm{C} / \mathrm{s}$. It is reminded that the validity of this equation has not been tested beyond the studied cooling rate 0.5 to $1.5^{\circ} \mathrm{C} / \mathrm{s}$ and temperature range 1370 to $1470^{\circ} \mathrm{C}$. Secondary dendrite arm spacing, $d_{2}$ $[\mu \mathrm{m}]$, can be estimated by Eq. (10).

$$
\begin{aligned}
d_{2}= & 123 \cdot \dot{T}^{-0.33} \cdot \exp \left(-0.281 C_{\mathrm{C}}+0.175 C_{\mathrm{Mn}}\right. \\
& \left.-0.063 C_{\mathrm{Cr}}-0.136 C_{\mathrm{Mo}}-0.091 C_{\mathrm{Ni}}\right) \ldots \ldots \ldots . .
\end{aligned}
$$

Here, $\dot{T}\left[{ }^{\circ} \mathrm{C} / \mathrm{s}\right]$ is the average cooling rate in the mushy zone obtained with the heat transfer model and $C_{i}[\mathrm{wt} \%]$ is the nominal composition of solute $i$. Usually the secondary dendrite arm spacing depends on the cooling rate according to $d_{2}=a R^{-n}$ and the exponent typically varies between 0.33 and 0.5 . In this study, the parameter a and the exponent $n$ has been statistically optimized using numerous experimental measurements of secondary dendrite arm spacing to add a composition dependency term to the exponent $n$. With high cooling rates, Eq. (10) results in a fine dendritic structure which restrains the effect of rapid cooling to delay the solidification event.

\section{Coupling of the Models}

The IDS and TEMPSIMU models have been coupled to predict the microstructure evolution in continuous casting. The general idea is that first, the thermo-physical material data are calculated with IDS for TEMPSIMU, which then calculates the cooling rates at each point in the strand. Then the microstructure evolutions are calculated by the IDS using these cooling rates. Because the IDS calculations must be repeated several times depending on the amount of the calculation points in the strand, a special SAC module ${ }^{16)}$ has been developed for this purpose. It calculates the microstructure evolutions through the strand using the local cooling rates and the local steel composition. The austenite decomposition model uses the nominal or interdendritic compositions of the steel in the calculations. However, the macrosegregation profiles of the solutes could be used as the input data if they are known.

The calculation procedure is not fully coupled, because the material properties for the heat transfer model are calculated by the mean solidification and cooling rates of the strand. Normally, the cooling rates vary at different points in the strand. More precisely, this should be taken into account when solving the heat transfer equations, but fortunately its influence on the results is quite small. The hardness distribution in the as-cast strand can also be predicted as well as the volume changes due to the density changes during cooling and phase transformations. The hardness calculation at room temperature is based on the empirical equations taking into account the phases, phase fractions, steel composition, and cooling rate. ${ }^{17,18)}$ Figure 3 illustrates the calculations of the SAC package. The figure shows the temperature distribution curves (calculated with TEMPSIMU) at various distances from the strand surface to the 


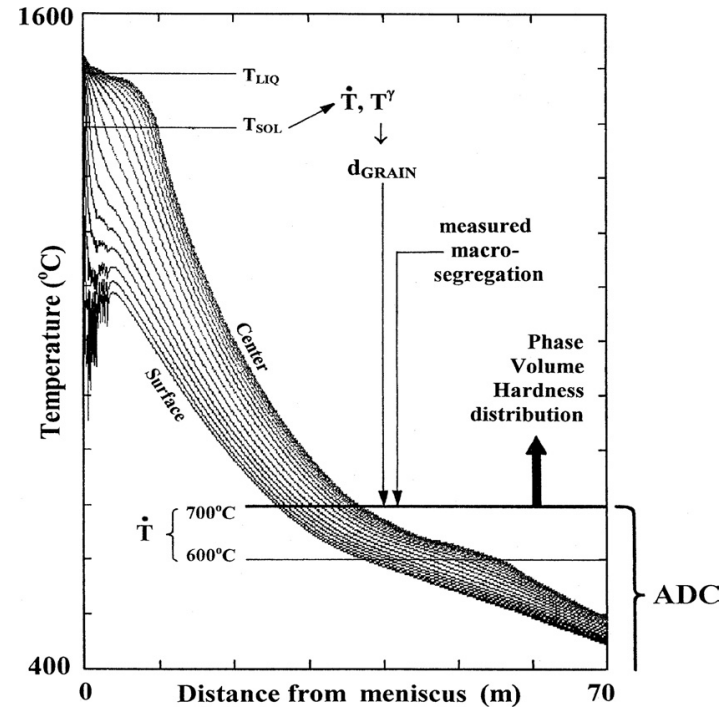

Fig. 3. Illustration of calculations in the SAC package.

centre. The curves are converted to cooling curves by changing the distance from meniscus to time. First, for ascast structure, nodal austenite grain sizes $\left(d_{\mathrm{G}}\right)$ are calculated using the nodal cooling rates below the solidus temperature (upper $\dot{T}$ ) obtained with TEMPSIMU and the temperature $T^{\gamma}$ obtained with IDS. Next, the nodal grain sizes are used with nodal compositions and nodal ADC cooling rates between $700^{\circ} \mathrm{C}$ and $600^{\circ} \mathrm{C}$ (lower $\dot{T}$ ) obtained with TEMPSIMU, to calculate nodal phase fraction, hardness and volume data.

\section{Case Examples}

The effect of carbon content (from 0 to $0.6 \%$ ) and cooling rate on the austenite grain size and $T^{\gamma}$ temperature was firstly calculated using the IDS model. The studied chemical composition was $0-0.6 \% \mathrm{C}+0.3 \% \mathrm{Si}+1 \% \mathrm{Mn}+$ $0.02 \% \mathrm{P}+0.02 \% \mathrm{~S}$. The calculation results are presented in Fig. 4. It can be seen that the grain size is the bigger the higher is the $T^{\gamma}$ temperature and the slower is the cooling rate below the solidification. The biggest grain size was obtained for the carbon content of about $0.15 \%$.

Secondly, SAC calculations were carried out for validation purpose. The validation was made by comparing the calculated microstructure, phase fractions and hardness distribution with measured data for as-cast blooms of Ovako Bar, Imatra Steelworks. The steel composition in this trial is given in Table 1. The experimental conditions were the following: bloom size $(280 \mathrm{~mm} \times 350 \mathrm{~mm})$, casting speed $(0.55 \mathrm{~m} / \mathrm{min})$, tundish superheat $\left(17^{\circ} \mathrm{C}\right)$, air-mist secondary cooling. To define the phase fractions, the samples were etched with Vilella's reagent $(5 \mathrm{~mL} \mathrm{HCl}+1 \mathrm{~g}$ picric acid $+100 \mathrm{~mL}$ ethanol) for $10 \mathrm{~s}$ and then photographed. Phases were defined from these photographs. For dendrite and grain structures, the etching for 40-60 s with a solution containing $40 \mathrm{~g} \mathrm{FeCl}_{3}+3 \mathrm{~g} \mathrm{CuCl}_{2}+4 \mathrm{~mL} \mathrm{HCl}$ in $500 \mathrm{~mL}$ of water was used. This etching agent made both dendrite and grain structures visible. The hardness was measured at room temperature from the as cast test samples. Firstly, the temperatures and cooling rates were calculated using the TEMPSIMU tool and the results were validated by the py-
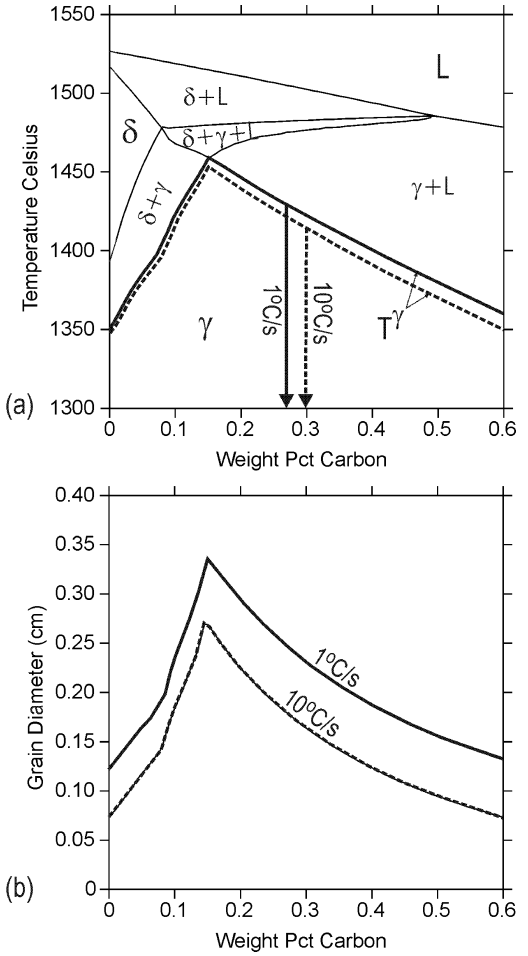

Fig. 4. The effect of carbon content and cooling rate on the $T^{\gamma}$ temperature (a) and austenite grain size (b) in steel with $0-0.6 \% \mathrm{C}+0.3 \% \mathrm{Si}+1 \% \mathrm{Mn}+0.02 \% \mathrm{P}+0.02 \% \mathrm{~S}$.

Table 1. Steel composition.

\begin{tabular}{|c|c|c|c|c|c|c|c|c|c|c|}
\hline \%C & \%Si & \%Mn & \%P & \%S & \%Cr & \%Ni & \%Mo & \%Ti & \%Cu & \%Al \\
\hline 0.41 & 0.248 & 0.904 & 0.009 & 0.025 & 1.022 & 0.198 & 0.244 & 0.005 & 0.182 & 0.056 \\
\hline
\end{tabular}

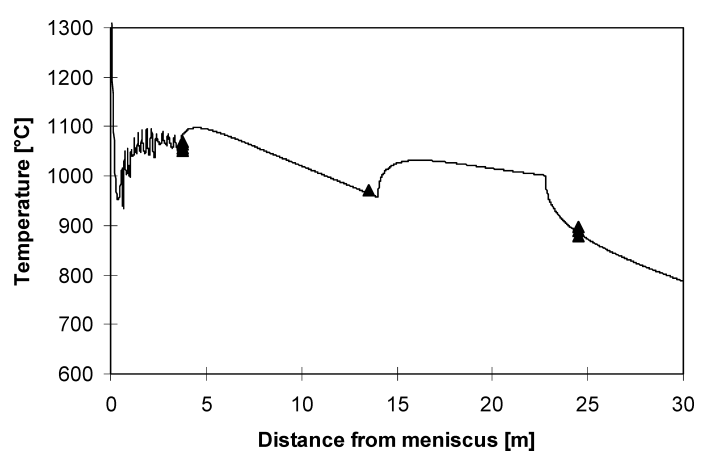

Fig. 5. Measured temperatures (symbols) and calculated surface temperatures (curve) on $\mathrm{x}$-face of a slab in the trial heat with casting speed of $0.55 \mathrm{~m} / \mathrm{min}$.

rometer measurements. Some results of the validation are presented in Fig. 5.

Figures 6 and 7 show some calculated and measured results for the as-cast blooms. The calculated results are presented at different distances (nodes) from the strand surface as $0 \mathrm{~mm}$ (strand surface), 5, 10, 16, 22, 30, 40, 50, 60, 70, $80,90,100,110,120,128,134$ and $140 \mathrm{~mm}$ (strand centre), and are compared with experimentally measured data. The nodal compositions (for the calculation of phase fractions) were estimated from the macro-segregation profiles measured at OVAKO Bar Imatra. Figure 6 shows the calculated and measured data for the austenite grain size. The finer grains near the surface area are due to the high cooling rates below the solidus in this area. The calculated distributions are quite similar and correlate well with the measured 


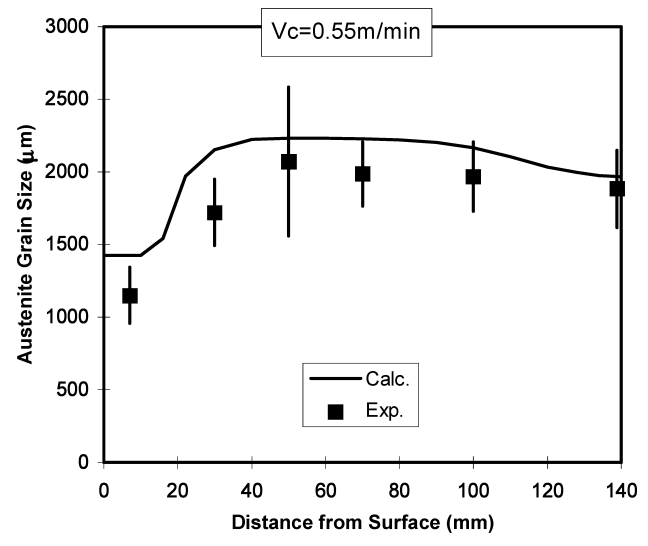

Fig. 6. Calculated austenite grain size distribution with some experimentally measured data points in as-cast bloom.

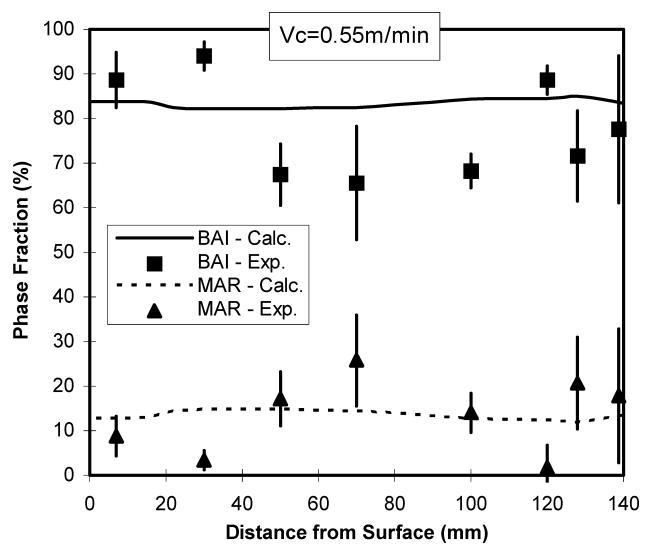

Fig. 7. Calculated distribution of bainite and martensite with some experimentally measured data points in as-cast bloom.

data. Figure 7 shows calculated distribution of bainite and martensite in the as-cast bloom. In the measurements, some scatter along the distance from the surface to the centre can be seen. This scatter is difficult to explain but as a measurement error, because the cooling and other conditions do not vary so much in the strand. But generally the calculated distribution of the phases correlates reasonably well with the measured data points. Figure 8 shows calculated secondary dendrite arm spacing distribution. The fine dendrite structure near the surface area results from the high mushy zone cooling rates in this area. On the whole, the calculated distributions correlate quite well with the measured data but close to the strand centre some scatter in the measurements can be seen. This can be partly due to the measurement error but also due to the fact that in the centre the growth is typically equiaxed and the dendrite arm spacing is more difficult to be defined there. Figure 9 shows calculated distribution of hardness and pro-eutectoid ferrite. The calculated distribution of hardness and the phases correlate reasonably well with the measured data points, although the calculated hardness is somewhat higher than the experimental values. It seems that the model gives a bit too high hardness values. The hardness calculation is partly based on statistical modeling and an improved non-linear fitting should be tested. The scatter in ferrite is difficult to be explained but as a measurement error.

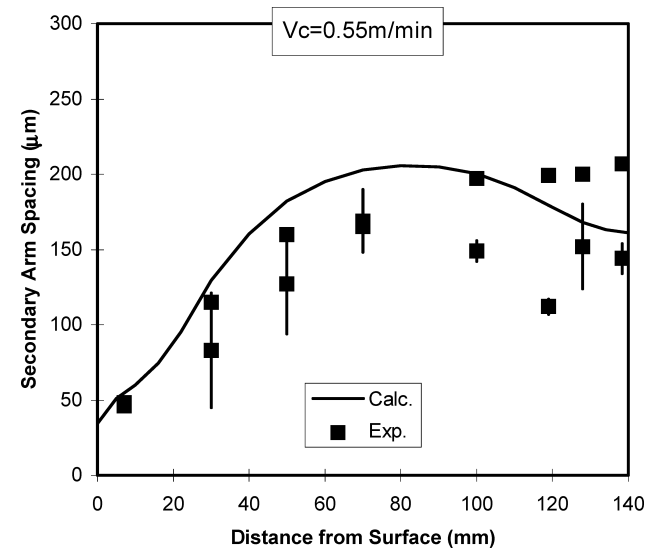

Fig. 8. Calculated secondary dendrite arm spacing distribution with some experimentally measured data points in the ascast bloom.

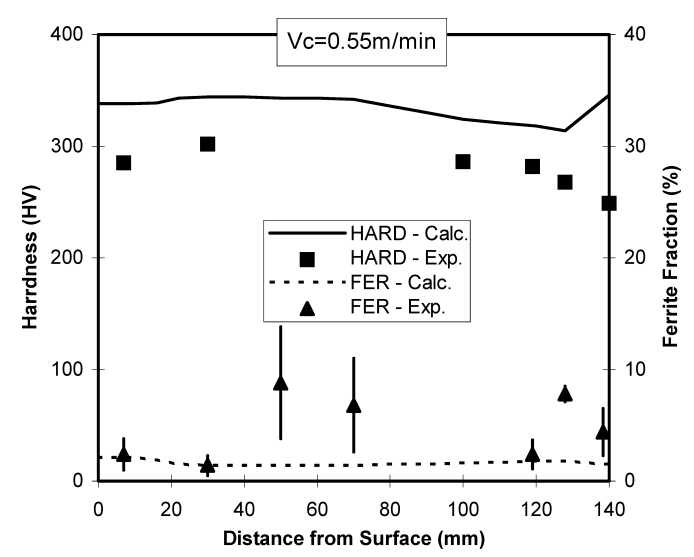

Fig. 9. Calculated distribution of hardness and pro-eutectoid ferrite with some experimentally measured data points in the as-cast bloom.

\section{Conclusions}

The aim of the long-term study was to develop models for heat transfer and solidification and to couple them together in order to simulate continuous casting process and the microstructures and properties in the as-cast strands.

A 3-dimensional steady state model (TEMPSIMU3D) and a dynamic heat transfer model (DYN3D) were developed to simulate continuous casting process. A solidification analysis package (IDS) was developed for simulation of solidification, phase transformations and material properties from liquid steel down to room temperature. Finally, the heat transfer model and the solidification model were coupled together to calculate micro-structural evolutions through the strand during continuous casting.

The article describes the models and some results calculated with the models. The coupled system was tested and assessed on a bloom caster. It seemed to predict quite accurately the phase transformations and micro-structural features like dendrite arm spacing and as-cast austenite grain size, as-cast phase fractions and as-cast hardness in continuous cast bloom throughout the whole strand. In the near future the models will be applied for on-line monitoring and control of industrial casters. 


\section{REFERENCES}

1) S. Louhenkilpi, J. Laine, T. Räisänen and T. Hätönen: 2nd Int. Conf. and Exhibition on New Developments in Metallurgical Process Technology, Riva del Garda, Italy, (2004).

2) T. Räisänen, S. Louhenkilpi, T. Hätönen, J. Toivanen, J. Laine and M. Kekäläinen: European Cong. on Computational Methods in Applied Sciences and Engineering ECCOMAS 2004, University of Jyväskylä, Jyväskylä, Finland, (2004).

3) S. Louhenkilpi, M. Mäkinen, S. Vapalahti, T. Räisänen and J. Laine: ICASP Advances in Solidification Processes, Proc. Int. Conf., Stockholm, Sweden, in press.

4) S. Louhenkilpi, T. Räisänen, S. Vapalahti, J. Laine and M. Mäkinen: Modeling of Casting, Welding and Advanced Solidification Processes XI, TMS, Warrendale, PA, (2006).

5) S. Louhenkilpi, M. Uoti, H. Kytönen and S. Vapalahti: Modeling of Casting, Welding and Advanced Solidification Processes X, TMS, Warrendale, PA, (2003), 733.

6) S. Louhenkilpi: Doctoral thesis, Acta Polytechnica Scandinavica, Chemical Technology Series No. 230, The Finnish Academy of Technology, Helsinki, (1995), 89.

7) J. Miettinen, H. Kytönen, S. Louhenkilpi and J. Laine: 12th IAS Steelmaking Seminar, Instituto Argentino de Siderurgia, Buenos Aires, (1999), 488.

8) H. Kytönen, M. Tolvanen, S. Louhenkilpi and L. Holappa: Modeling of Casting, Welding and Advanced Solidification Processes VIII,
The Minerals, Metals \& Materials Society, Warrendale, Pennsylvania, (1998), 631.

9) J. Miettinen, Doctoral thesis, Acta Polytechnica Scandinavica, Chemical Technology and Metallurgy Series, No. 207, The Finnish Academy of Technology, Helsinki, (1992), 81.

10) J. Miettinen: Report TKK-MK-78, Helsinki University of Technology Publications in Materials Science and Metallurgy, TKK, Espoo, (1999), 56.

11) J. Miettinen and J. Laine: Report TKK-V-B121, Helsinki University of Technology, TKK, Espoo, (1996), 61.

12) J. Miettinen and S. Louhenkilpi: Metall. Mater. Trans. B, 25 (1994), 909.

13) J. Miettinen: Ironmaking Steelmaking, 23 (1996), 346

14) J. Miettinen: Report TKK-MK-10, Helsinki University of Technology Publications in Materials Science and Metallurgy, TKK, Espoo, (1997), 69.

15) K. Yasumoto, T. Nagamichi, Y. Maehara and K. Gunji: Tetsu-toHagané, 73 (1987), 1738.

16) J. Miettinen: Report TKK-MK-50, Helsinki University of Technology Publications in Materials Science and Metallurgy, TKK, Espoo, (1998), 10.

17) J. Miettinen, S. Louhenkilpi and L. Holappa: ISIJ Int., 36 (1996), S183.

18) M. Atkins: Atlas of Continuous Cooling Transformation Diagrams for Engineering Steels, British Steel Corporation, Sheffield, (1977), 260 . 